\title{
Lymphangioma circumscriptum of the eyelids and conjunctiva
}

\author{
R R Goble, M A Frangoulis
}

\begin{abstract}
A case of lymphangioma circumscriptum of the eyelids and conjunctiva is described. The classification of this disease is given.
\end{abstract}

The term 'lymphangioma circumscriptum' was introduced by Morris et al in 1889, 'though the first case report had been described 20 years earlier. ${ }^{2}$ It is an uncommon condition characterised by an area or areas of skin covered in clusters of persistent vesicles containing colourless fluid and sometimes blood. There may be associated subcutaneous thickening and cysts. It usually presents at birth or during early childhood, and the skin of the proximal limb and anterolateral trunk is most commonly involved..$^{34}$ We present a case with involvement of eyelid and conjunctiva.

\section{Case report}

A 19-year-old woman presented with a swollen right upper eyelid and numerous vesicles on the medial bulbar conjunctiva and eyelid margins. Some of the vesicles had bled following minor trauma. The lesions had first been noticed 10 years previously on the right caruncle and had been excised. They recurred two years after that operation, and more vesicles appeared on the adjacent conjunctiva and eyelids.

On examination the right medial canthus was covered in clusters of vesicles $1 \mathrm{~mm}$ in diameter. Most vesicles contained clear fluid, but several

Accepted for publication

19 April 1990

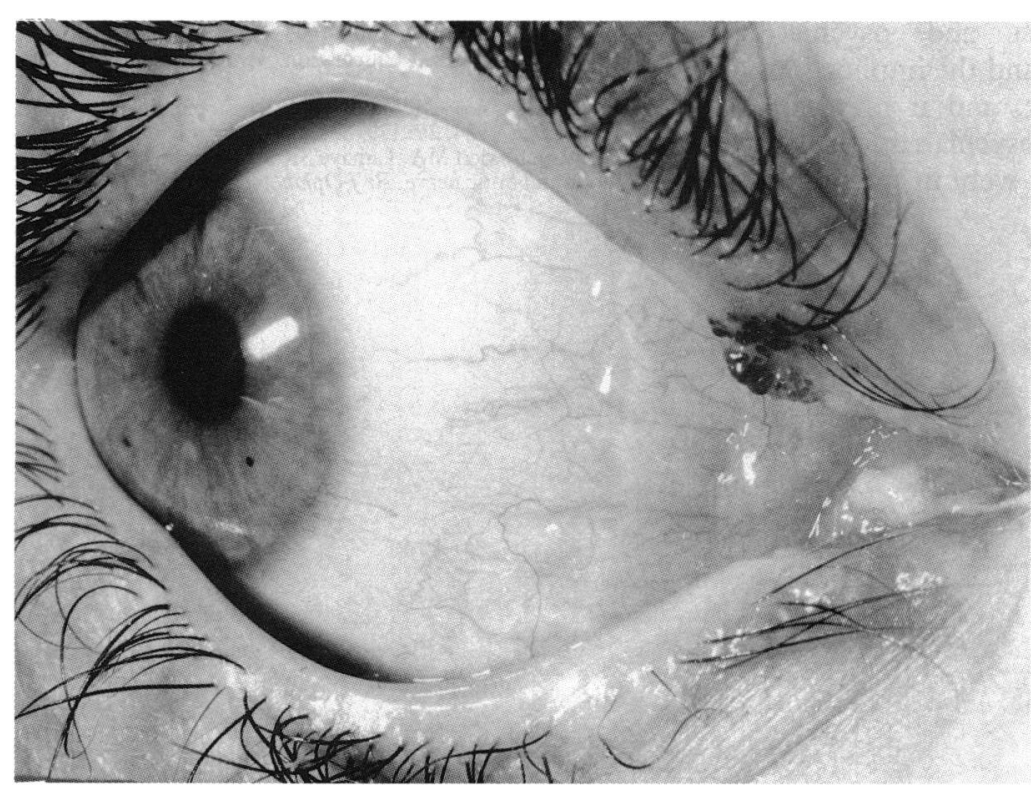

Figure 1 Lymphangioma circumscriptum of the right eye. There are a cluster of blood filled vesicles adjacent to the upper punctum with numerous clear vesicles involving the caruncle and medial bulbar conjunctiva and among the eyelashes. were blood filled (Fig 1). Both upper and lower eyelids were thickened medially, producing a mechanical ptosis of 2-3 mm. The lid lesions fluctuated in severity and were at worst only moderately noticeable. The conjunctival vesicles also varied in size, occasionally appearing pseudochemotic when confluent. No other skin lesions were found, and the ocular examination gave otherwise normal results, with no evidence of orbital involvement.

A clinical diagnosis of lymphangioma circumscriptum was supported by the previous biopsy report of lymphangiectasia. The eyelid margins were treated by cryotherapy with a liquid nitrogen spray to reduce the number of vesicles distorting the normal anatomy. It was felt that treatment to pretarsal tissue would fail to treat the deeper lesions adequately and would cause scarring. The conjunctival vesicles were the least noticeable and required no treatment.

Two months later there had been complete resolution of the blood filled marginal vesicles, with a minimal residual ptosis. Cosmesis was improved, and the patient refused any further treatment.

\section{Discussion}

Lymphangioma circumscriptum is thought to represent a developmental abnormality. The subepidermal lymphatic 'vesicles' are endothelium-lined spaces which are completely separate from the normal lymphatic system. ${ }^{56}$ Peachey et al described three groups of lymphangioma circumscriptum ${ }^{6}$ :

(1) Classical lesions involving larger skin areas, which are produced by rhythmically contracting muscle coated cisterns in the subcutaneous tissues. ${ }^{5}$ Other authors classify the subcutaneous lesions seperately as lymphangioma cavernosum. ${ }^{4}$

(2) Superficial lesions involving smaller areas with no subcutaneous abnormalities.

(3) Spongy lesions, found exclusively in areas where skin and mucosa are interwoven with striated muscle, such as tongue, lips, and eyelids. In the last group there are fewer vesicles and numerous irregular superficial dermal lymphatic spaces.

Treatment of superficial lymphangioma circumscriptum and the smaller classical lesions by surgical excision of skin and underlying subcutaneous tissue is $91-100 \%$ curative. $^{34}$ The larger classical lesions tend to recur following surgery, as the extent of subcutaneous involvement may be difficult to define, making complete excision impossible. Cautery, cryotherapy, radiotherapy, and carbon dioxide laser vaporisation have been used in treating surgically inaccessible sites, to improve cosmesis, and to 
prevent complications. However, none of these methods of treatment prevent recurrences in classical lesions. ${ }^{6-9}$ It is difficult to evaluate different types of treatment in patients with lymphangioma circumscriptum because there have been no comparative trials.

1 Unna PG, Morris M, Duhring LA, Leloir H. International atlas of rare skin diseases. London: Lewis, 1889:1-4.

2 Fox T, Fox TC. On the case of lymphangiectodes with an account of the histology of the growth. Trans Pathol Soc 1879; 30: $470-6$.
3 Browse NL, Whimster IW, Stewart G, Helm CW, Wood JJ. Surgical management of 'lymphangioma circumscriptum'. Brf Surg 1986; 73: 585-8.

4 Flanagan BP Helwig EB. Cutaneous lymphangioma. Arch Dermatol 1977; 113: 24-30.

5 Whimster IW. The pathology of lymphangioma circumscriptum. Brf Derm 1976; 94: 473-86.

6 Peachey RDG, Lim C-C, Whimster IW. Lymphangioma of the skin. Brf Derm 1970; 83: 519-27.

7 Van Cauwelaert P, Gruwez JA. Experience with lymphangioma. Lymphology 1978; 11: 43-8.

8 O'Cathail S, Rostom AY, Johnson ML. Successful control of lymphangioma circumscriptum by superficial $x$-rays.

9 Eliezri ZD, Sklar JA. Lymphangioma circumscriptum: review and evaluation of carbon dioxide laser vapourisation. f Dermatol Surg Oncol 1988; 14: 357-64. 